\title{
Practice-Based Innovations: More Relevant and Transportable Than NIH-funded Studies
}

\author{
Rebecca S. Etz, PhD, Karissa A. Hahn, MPH, Martha M. Gonzalez, BA, \\ Benjamin F. Crabtree, PhD, and Kurt C. Stange, MD, MPH
}

In 2003, the National Institutes of Health (NIH) created a translational science funding stream to foster widespread, practice-based dissemination of scientific evidence. A decade later, our study of a national cohort of innovative practices suggests that effective dissemination continues to be prevented by the limited biomedical focus of funded research, conventional research strategies, and failure to report contextual factors. (J Am Board Fam Med 2014;27:738-739.)

Keywords: Health Policy, Practice-based Research, Primary Health Care, Program Sustainability, Translational Medical Science

We previously published an assessment of US primary care workforce innovations that involved a review of more than 4400 abstracts and more than 350 articles published since $2000 .{ }^{1}$ Based on the combined experience of the research team, we determined that the literature did not capture the observable landscape of primary care innovation. We therefore followed the first study with a purposeful sampling of investigators based on the literature and snowball sampling to follow up leads. In the second study, we identified and interviewed 250 primary care leaders associated

This article was externally peer reviewed.

Submitted 4 February 2014; revised 16 April 2014; accepted 21 April 2014.

From the Department of Family Medicine and Population Health, Virginia Commonwealth University, Richmond (RSE, MG); the Department of Family Medicine and Community Health, Rutgers University Robert Wood Johnson Medical School, New Brunswick, NJ (KAH, BFC); and the Departments of Family and Community Health, Epidemiology and Biostatistics, and Sociology, Case Western Reserve University, Cleveland, OH (KCS).

Funding: This study was funded by the Robert Wood Johnson Foundation (grant no. 68461).

Conflict of interest: none declared.

Corresponding author: Rebecca S. Etz, PhD, Department of Family Medicine and Population Health, Virginia Commonwealth University, 830 East Main St, PO Box 980101, Richmond, VA 23298-0101 (E-mail: Rsetz@vcu.edu).

See Related Commentary on Page 736. with 190 practice settings at the cutting edge of workforce innovation with the intention of identifying exemplars for further investigation. ${ }^{2}$

The majority of published accounts of primary care workforce innovation focus on specific diseases or disease clusters and a fidelity to research design, resulting in incremental innovations that are not sustainable. In addition, National Institutes of Health-funded studies seem to favor biomedical data, thus missing many of the contextual factors critical to localized success. In contrast, the innovative practices of our study developed solutions to everyday problems, informed by awareness of local context and funding constraints. Such solutions, built on practicebased evidence, ${ }^{3}$ enjoy greater sustainability, improved attention to context-specific preconditions, fluid adaptations to workflow, and greater potential for translation (Table 1). Many practices report visiting peer sites as part of their problem-solving approach, noting that understanding context is critical to disseminating productive models.

Context-based innovations that are primarily grounded in the everyday competing demands of high-quality primary care settings are more likely to create sustainable solutions to real-world problems. Such practice-based solutions learn from cycles of failure and adaptation and ultimately foster effective change at a faster pace than solutions currently found in the published 
Table 1. Contrast of Innovations Informed by National Institutes of Health (NIH)-Funded Studies and Practice Innovators

\begin{tabular}{|c|c|}
\hline Characteristics of NIH-Funded Studies & Characteristics of Studies Based on Everyday Practice \\
\hline Begin with identified gap in the literature & Begin with identified local need \\
\hline Structured by idealized conceptual framework & Structured by awareness of known local assets \\
\hline Design based on infusion of unsustainable resources & Design is responsive to local constraints \\
\hline Grant often adds responsibilities to existing jobs & $\begin{array}{l}\text { Design often redistributes responsibilities based on new services } \\
\text { offered }\end{array}$ \\
\hline Develop grant-dependent roles outside the practices & Develop relationships between practices and community resources \\
\hline Designed to minimize impact on physicians & Designed to redefine physician role \\
\hline $\begin{array}{l}\text { Grant avoids perturbing the system or adding new } \\
\text { outside system }\end{array}$ & Design intends to create a learning system \\
\hline Intervention is responsive to pathology & Intervention is responsive to patient experiences of health and illness \\
\hline $\begin{array}{l}\text { Funded interventions engage idealized patients as } \\
\text { represented in the literature }\end{array}$ & Interventions engage real patients as represented in the practice \\
\hline Based on incremental change & Based on punctuated change or whole-practice transformation \\
\hline $\begin{array}{l}\text { Funded interventions almost exclusively motivated by } \\
\text { disease-specific aims }\end{array}$ & $\begin{array}{l}\text { Innovations almost exclusively motivated by the health of patients } \\
\text { and community }\end{array}$ \\
\hline
\end{tabular}

literature. To meet the innovation needs of primary care, and the health needs of the US population, funders and funding mechanisms must equally embrace fidelity, flexibility, contextual relevance, and grounding in the reality of everyday primary care practice as necessary elements for successful translational funding requests. The National Institutes of Health should also support the creation and adoption of new metrics and methods appropriate for testing and evaluating practice innovation to capture contextual learning.

\section{References}

1. Friedman A, Hahn KA, Etz R, et al. A typology of primary care workforce innovations in the United States since 2000. Med Care 2014;52:101-11.

2. Ladden MD, Bodenheimer T, Fishman NW, et al. The emerging primary care workforce: preliminary observations from the primary care team: learning from effective ambulatory practices project. Acad Med 2013;88:1830-4.

3. Green LW. From research to "best practices" in other settings and populations. Am J Health Behav 2001;25: $165-78$. 